\title{
Basic principles and recommendations in clinical and field science research: 2018 update
}

\author{
Johnny Padulo 1 \\ Francesco Oliva ${ }^{2}$ \\ Antonio Frizziero ${ }^{3}$ \\ Nicola Maffulli ${ }^{4}$
}

1 Psychology, University e-Campus, Novedrate, Italy

2 Department of Orthopaedics and Traumatology, University of Rome "Tor Vergata", Rome, Italy

3 Department of Physical and Rehabilitation Medicine, University of Padua, Italy

${ }^{4}$ Department of Musculoskeletal Disoders, University of Salerno, Italy; Queen Mary University of London, Barts and The London School of Medicine and Dentistry, Mile End Hospital, London, England; Institute of Science and Technology in Medicine, Keele University School of Medicine, Stoke on Trent, England

\section{Corresponding author:}

Nicola Maffulli

Department of Musculoskeletal Disorders

School of Medicine and Surgery,

University of Salerno;

Queen Mary University of London

Barts and the London School of Medicine and Dentistry

Centre for Sports and Exercise Medicine

Mile End Hospital 275 Bancroft Road

E1 4DG, London, England, UK

Tel.: +447989358279

E-mail: n.maffulli@qmul.ac.uk

\section{Summary}

The proper design and implementation of a scientific study as well as a balanced and well-supported evaluation and interpretation of its main findings are of crucial importance when reporting and disseminating research. Also accountability, funding acknowledgment and adequately declaring any conflict of interest play a major role in science. Since the Muscle, Ligaments and Tendons Journal (MLTJ) is committed to the highest scientific and ethical standards, we encourage all authors to take into account and to comply, as much as possible, to the contents and issues dis- cussed in this official editorial. This could be useful for improving the quality of the manuscripts, as well as to stimulate interest and debate and to promote constructive change, reflecting upon uses and misuses within our disciplines belonging to the field of "Clinical and Sport - Science Research".

KEY WORDS: best practice, conflict of interest, design, experimental approach, ethical standard, statement, evidence-based medicine, level of evidence.

\section{Introduction}

In the last two years, research opportunities, approaches and environment have been rapidly evolving as well as associated ethical issues. In the original 2016 Muscle, Ligaments and Tendons Journal (MLTJ) editorial ${ }^{1}$, we described the best research practices, taking into consideration ethical aspects and international laws, providing a specific guideline for researchers working within the vast, interdisciplinary field of "Clinical and Sport - Science Research". Experiments are routinely designed and collected from investigators for various purposes, but, unfortunately, are sometimes reported with a lack of details that could, instead, facilitate their reproducibility; therefore, the current update specifically refers to:

1. the most important ethical guidelines in the field of sports sciences, with a focus on the Declaration of Helsinki and its amendments over the years;

2. investigations involving human/animal subjects, and in particular young participants and children;

3. clarification on the level of the evidence;

4. clarification on usefulness to properly structure a scientific article;

5. clarification on cover letter.

\section{Ethical guidelines}

The most important ethical guidelines in the field of sports sciences are listed in Table I. Other outstanding ethical codes are those of the United Nations Educational, Scientific and Cultural Organization (UNESCO $)^{2}$, the International Federation of Sports Medicine (IFSM)/Fédération Internationale de Médecine du Sport (FIMS) ${ }^{3}$, among others. 


\section{J. Padulo et al.}

Table I. The most important ethical guidelines in the field of sports sciences.

\begin{tabular}{ll}
\hline Year & Ethical guidelines \\
\hline 1947 & Nuremberg Code \\
1964-on (last revised 2013) & Declaration of Helsinki \\
1981 -on (last revised 2010) & World Medical Association Declaration on Principles \\
& of Health Care for Sports Medicine \\
2009 -on & Olympic Movement Medical Code \\
\hline
\end{tabular}

\section{Declaration of Helsinki}

Among ethical guidelines, Declaration of Helsinki represents an undoubtedly milestone ${ }^{4}$. The World Medical Association (WMA) has revised the Declaration of Helsinki, which in its latest version ensures increased protection for people taking part in medical research, and in particular for vulnerable groups. Authors should conduct their research involving human participants ethically according to the principles of the Declaration of Helsinki ${ }^{5}$.

\section{Research involving human participants}

Research involving human subjects should:

- respect the participant's rights, safety and wellbeing;

- be approved by an appropriate ethical committee;

- have a clearly justifiable and properly developed experimental approach (design - statistical analysis), in accordance with the Declaration of Helsinki;

- provide information regarding "funding - sponsor - other potential conflicts of interest (which should be clarified and detailed);

- an adequate compensation and treatment for each participant.
Research involving young participants:

- for subjects aged until 18 years age, the informed consent/assent should be provided with appropriate, written documentation by parent/ guardian/tutor;

- informed consent (also for adults) should be exhaustive, clearly readable ${ }^{6}$;

- issues of privacy and confidentiality (also for adults) should be considered in their broader meaning, that is to say beyond what is strictly legally required (i.e., images video recording, data set with name and surname $)^{7}$;

- particular confidentiality is required when the investigator collects data at the worksite or from the Internet ${ }^{8}$. Unfortunately, the particularly challenging sports climate and environment may exacerbate pressures on clinicians to break patient confidentiality ${ }^{9}$;

- each detail (also for adults) about the privacy and confidentiality have been considered beyond what is legally required.

\section{Levels of evidence}

The "National Cancer Institute" defines levels of evidence as "a ranking system" used to describe the

Table II. Level of Evidence.

\begin{tabular}{|c|c|}
\hline Level of evidence & Type of study \\
\hline $1 \mathrm{a}$ & Systematic review of (homogeneous) randomized controlled trials \\
\hline $1 b$ & Individual randomized controlled trials (with narrow confidence intervals) \\
\hline \multirow[t]{2}{*}{$2 a$} & Systematic review of (homogeneous) cohort studies of "exposed" \\
\hline & and "unexposed" subjects \\
\hline $2 b$ & Individual cohort study/low-quality randomized controlled trials \\
\hline $3 a$ & Systematic review of (homogeneous) case-control studies \\
\hline $3 b$ & Individual case-control studies \\
\hline 4 & Case series, low-quality cohort or case-control studies \\
\hline 5 & $\begin{array}{l}\text { Expert opinions based on non systematic reviews of result or mechanistic } \\
\text { studies }\end{array}$ \\
\hline
\end{tabular}


strength of the results measured in a clinical trial or research study. Levels of evidence for therapy or prevention. Material adapted from the recommendations at the centre for evidence-based medicine in Oxford (Tab. II) (courtesy Dr. D.L. Sackett) ${ }^{10,11}$.

\section{I performed experiments and I have results. Wow and now?}

Writing a scientific article is not an easy task, but it is definitely a great satisfaction to be able to conclude and publish it. Indeed, each publication is a service we make to the entire scientific community and to the advancement of science even before our personal career. We suggest each author to read this Editori$\mathrm{al}^{12}$ and to describe ethically the author/s contributions in the last part of each manuscript by citing the aforementioned publication ${ }^{12}$.

\section{Cover letter}

A good cover letter is a crucial part of the manuscript submission to MLTJ. It is not simply an archaic form of communication that is becoming obsolete in a digital world; rather, it should be viewed as an opportunity to convey many important pieces of information about a manuscript to the Chief editors. Manuscripts submitted to MLTJ will be first filter an editorial evaluation stage, but as professional editors, we are not experts in every scientific field that the journal covers. Providing context for the paper in a cover letter not only can help the editors reach a quicker decision but also can sometimes tip the balance in favor of sending a borderline paper out for peer review. Here are some practical tips for potential authors (http://blogs.nature.com/methagora/2013/09/how-to-write-a-cover-letter.html).

Authors are required to confirm (after read and turn up the first-second guidelines ${ }^{1,13}$ ) their compliance to the ethical and scientific standards here discussed, by formally citing this editorial within the methods section of their own manuscript. Further, MLTJ welcomes methodological papers, which address to solve those key issues that hamper widespread use of techniques in the field of "Clinical and Sport - Science Research".

\section{References}

1. Padulo J, Oliva F, Frizziero A, Maffulli N. Muscles, Ligaments and Tendons Journal - Basic principles and recommendations in clinical and field science research: 2016 update. MLTJ. 2016;6(1):1-5.

2. UNESCO. http://portal unesco org/education/en/ev phpURL_ID $=2223 \&$ URL_DO=DO_TOPIC\&URL_SEC TION=201 html 2016.

3. FIMS. www fims org/about/code-ethics/ 2016.

4. Stewart RJ, Reider B. The Ethics of Sports Medicine Research. Clin Sports Med. 2016;35(2):303-314.

5. World Medical Association. World Medical Association. Declaration of Helsinki: Ethical principles for medical research involving human subjects. JAMA. 2013;310:2191-2194.

6. Cardinal BJ, Martin JJ, Sachs ML. Readability of written informed consent forms used in exercise and sport psychology research. Res Q Exerc Sport. 1996;67(3):360-362.

7. Anderson L. Contractual obligations and the sharing of confidential health information in sport. J Med Ethics. 2008;34(9): e6.

8. Shephard RJ. Ethics in exercise science research. Sports Med. 2002;32(3):169-183.

9. Malcolm D. Confidentiality in Sports Medicine. Clin Sports Med. 2016;35(2):205-215.

10. Guyatt GH, Sackett DL, Cook DJ. Users' guides to the medical literature. II. How to use an article about therapy or prevention. A. Are the results of the study valid? Evidence-Based Medicine Working Group. JAMA. 1993;270(21):2598-2601.

11. Oxman AD, Sackett DL, Guyatt GH. Users' guides to the medical literature. I. How to get started. The Evidence-Based Medicine Working Group. JAMA. 1993;270(17):2093-2095.

12. Padulo J, De Giorgio A, Oliva F, Frizziero A, Maffulli N. I performed experiments and I have results. Wow and now? MLTJ. 2017;7(3):403-410.

13. Padulo J, Oliva F, Frizziero A, Maffulli N. Muscle, Ligaments and Tendons Journal. Basic principles and recommendations in clinical and field science research. MLTJ. 2013;3(4):250252. 